\title{
Delirium following vascular surgery: increased incidence with preoperative $\beta$-blocker administration
}

\section{Le delirium après une chirurgie vasculaire: incidence accrue lors de l'administration préopératoire de $\beta$-bloquants}

\author{
Rita Katznelson, MD · George Djaiani, MD • Nicholas Mitsakakis, MSc • \\ Thomas F. Lindsay, MDCM · Gordon Tait, PhD · Zeev Friedman, MD · \\ Marcin Wasowicz, MD · W. Scott Beattie, MD, PhD
}

Received: 27 April 2009/Accepted: 6 July 2009/Published online: 27 August 2009

(C) Canadian Anesthesiologists' Society 2009

\begin{abstract}
Purpose To determine if there is an association between perioperative administration of beta-blockers and postoperative delirium in patients undergoing vascular surgery.

Methods After Institutional Review Board approval, data were retrospectively collected on patients who underwent vascular surgery in an academic hospital during the period January 2006 to January 2007. Patients with preoperative altered level of consciousness, carotid endarterectomy, or
\end{abstract}

This article is accompanied by an editorial. Please see Can J Anesth 2009; 56: 11.

R. Katznelson, MD · G. Djaiani, MD · N. Mitsakakis, MSc

G. Tait, $\mathrm{PhD} \cdot \mathrm{Z}$. Friedman, MD · M. Wasowicz, MD .

W. S. Beattie, MD, PhD

Department of Anesthesia and Pain Management, University

of Toronto, Toronto, ON, Canada

R. Katznelson, MD · G. Djaiani, MD - N. Mitsakakis, MSc ·

G. Tait, $\mathrm{PhD} \cdot \mathrm{Z}$. Friedman, MD - M. Wasowicz, MD ·

W. S. Beattie, MD, PhD

Department of Anesthesia and Pain Management, University

Health Network, Toronto, ON, Canada

T. F. Lindsay, MDCM

Department of Surgery, Division of Vascular Surgery,

University of Toronto, Toronto, ON, Canada

T. F. Lindsay, MDCM

Department of Surgery, University Health Network, Toronto,

ON, Canada

R. Katznelson, MD ( $\square)$

Department of Anesthesia and Pain Management, Toronto

General Hospital, Eaton North 3-453, 200 Elizabeth Street,

Toronto, ON M5G 2C4, Canada

e-mail: rita.katznelson@uhn.on.ca discharge within 24 h of surgery were excluded from the study. Identification of delirium was based on evaluation of the level of consciousness with the NEECHAM Confusion Scale and/or a chart-based instrument for delirium. Multivariable logistic regression analysis was used to identify independent perioperative predictors of postoperative delirium. Beta-blockers were tested for a potential effect.

Results The incidence of postoperative delirium was 128/ $582(22 \%)$. Independent predictors included age (OR 1.04, 95\% CI [1.02-1.07]), history of cerebrovascular accident/ transient ischemic attack (OR 2.64, 95\% CI [1.57-4.55]), and depression (OR 3.56, 95\% CI [1.53-8.28]). Open aortic reconstruction was associated with an OR of 5.34, 95\% CI (2.54-11.2) and amputation with an OR of 4.66, 95\% CI (1.96-11.09). Preoperative beta-blocker administration increased the odds of postoperative delirium 2.06 times (95\% CI [1.18-3.6]). Statin administration reduced the odds of delirium by $44 \%$ (95\% CI [0.37-0.88]). The model was reliable (Hosmer-Lemeshow test, $P=0.72$ ) and discriminative (area under the receiver operating characteristic [ROC] curve $=0.729$ ).

Conclusions Preoperative administration of beta-blockers is associated with an increased risk of postoperative delirium after vascular surgery. Conversely, preoperative statin administration is associated with a lower risk of postoperative delirium. A randomized prospective controlled trial is required to validate these findings.

Résumé

Objectif Déterminer s'il existe un lien entre l'administration périopératoire de bêta-bloquants et le delirium postopératoire chez les patients subissant une chirurgie vasculaire. 
Méthode Après avoir obtenu l'accord du Comité d'éthique de notre institution, nous avons rétrospectivement récolté les données concernant les patients ayant subi une chirurgie vasculaire dans un hopital universitaire entre janvier 2006 et janvier 2007. Les patients ayant manifesté un niveau de conscience préopératoire altéré, subi une endartériectomie de la carotide ou reçu leur congé dans les 24 heures suivant la chirurgie ont été exclus de l'étude. Le dépistage du delirium s'est fondé sur l'évaluation $d u$ niveau de conscience à l'aide de l'échelle de confusion NEECHAM et/ou d'un instrument d'évaluation du delirium par diagramme. L'analyse multivariée par régression logistique a été utilisée pour identifier les prédicteurs périopératoires indépendants de delirium postopératoire. Les bêta-bloquants ont été testés afin de déterminer leur effet potentiel.

Résultats L'incidence de delirium postopératoire a été de 128/582 (22 \%). L'âge (RC 1,04, IC 95 \% [1,02-1,07]), les antécédents d'accident vasculaire cérébral/d'accident ischémique transitoire (RC 2,64, IC $95 \%$ [1,57-4,55]) et la dépression (RC 3,56, IC $95 \%$ [1,53-8,28]) étaient des prédicteurs indépendants. La reconstruction aortique ouverte a été associée à un RC de 5,34, IC $95 \%$ (2,5411,2) et l'amputation à un RC de 4,66, IC $95 \%$ (1,9611,09). L'administration préopératoire de bêta-bloquants a augmenté la probabilité d'un delirium postopératoire de 2,06 fois (IC $95 \%$ [1,18-3,6]). L'administration de statine a réduit la probabilité de delirium de $44 \%$ (IC $95 \%$ [0,370,88]). Le modèle était fiable (test de Hosmer-Lemeshow, $P=0,72$ ) et discriminatif (surface sous la courbe $R O C=0,729)$.

Conclusion L'administration préopératoire de bêtabloquants est associée à un risque accru de delirium postopératoire à la suite d'une chirurgie vasculaire. Inversement, l'administration préopératoire de statine est associée à une réduction du risque de delirium postopératoire. Une étude prospective randomisée contrôlée est nécessaire pour valider ces résultats.

Delirium is a common and well-recognized complication after vascular surgery that affects over $30 \%$ of patients ${ }^{1-4}$ and is associated with prolonged length of stay, ${ }^{5}$ increased health care costs, ${ }^{6}$ and higher morbidity and mortality. ${ }^{7-10}$ Furthermore, patients with delirium are more likely to be discharged to either intermediate- or long-term care facilities, ${ }^{5}$ increasing the primary admission health care costs to the community.

Vascular surgery is associated with increased risk of perioperative cardiac, renal, and cerebrovascular complications. ${ }^{11}$ The current perioperative guidelines recommend the use of beta-blockers in high-risk cardiac patients undergoing vascular surgery. ${ }^{12}$ These recommendations stem from the demonstration that perioperative treatment with betablockers decreased the incidence of cardiac complications and death in very high-risk vascular surgery patients. ${ }^{13}$

Conversely, recent studies reporting the effects of preoperative beta-blockers on outcomes after non-cardiac (including vascular) surgery produced controversial results ${ }^{14-17}$ and could not demonstrate risk reduction. The results of a meta-analysis after these trials suggested an increase in postoperative stroke. ${ }^{17}$ The largest randomized controlled trial evaluating perioperative outcomes in patients receiving beta-blocker therapy (POISE) demonstrated a significant reduction in perioperative myocardial infarction in patients receiving metoprolol. ${ }^{18}$ However, this reduction was associated with a significant increase in the stroke rate and overall mortality.

Thus, while beta-blockers unquestionably have the potential to increase adverse events on the central nervous system, ${ }^{19}$ their effect on postoperative delirium after vascular surgery has not been previously studied. The primary objective of the current study was to determine whether there is an association between perioperative administration of beta-blockers and postoperative delirium in a large cohort of patients undergoing vascular surgery. A secondary objective was to confirm the previously found direct protective effect of statin therapy on postoperative delirium. ${ }^{20}$ We hypothesized that preoperative administration of beta-blocker therapy would increase the risk of postoperative delirium/confusion in the vascular surgical population.

\section{Materials and methods}

After Institutional Ethics Review Board approval, data were collected on all patients who were undergoing both elective and emergency vascular surgery at Toronto General Hospital during the period January 2006 to January 2007.

Patients were excluded from the analysis based on the following criteria: a preoperative NEECHAM Confusion Scale $<25$, history of dementia and/or abnormal level of consciousness prior to surgery, hospital admission for $<24 \mathrm{~h}$, more than one procedure was recorded during the study period, or the patient had undergone a carotid endarterectomy. The presence or absence of delirium was used to dichotomize the patient groups.

Prospective assessment of delirium

Identification of delirium after vascular surgery was based on an evaluation of level of consciousness with the NEECHAM Confusion Scale ${ }^{21}$ and a chart-based instrument for delirium. $^{22}$ As previously described, the NEECHAM 
Table 1 The NEECHAM Confusion Scale ${ }^{21}$

\begin{tabular}{lc}
\hline & Score \\
\hline Level 1: Processing & \\
$\quad$ Attention/alertness/responsiveness & $0-4$ \\
Command (recognition) & $0-5$ \\
Orientation/memory/speech & $0-5$ \\
Level 2: Behavior & \\
Appearance/Hygiene & $0-2$ \\
Motor & $0-4$ \\
Verbal & $0-4$ \\
Level 3: Physiologic control & \\
Vital Function Stability & $0-2$ \\
Oxygen Saturation Stability & $0-2$ \\
Urinary Continence Control & $0-2$ \\
Total Score & $0-30$ \\
\hline
\end{tabular}

assessment is part of the standard institutional patient evaluation after vascular and cardiac surgery. ${ }^{23}$ The scale includes nine items separated into three categories that estimate the patient's level of processing information, level of behavior, and physiological state (Table 1). The values 27-30 correspond to normal, 25-26 indicate the patient is "at risk" of confusion, 20-24 indicate "mild confusion", while $<20$ indicates "moderate to severe confusion". The NEECHAM assessment was performed daily until the patient was discharged.

Each 24-h period, patients who were admitted to the intensive care unit were assessed for the presence of delirium based on the previously described validated chart review. ${ }^{22}$ The review was performed by a physician who looked for evidence of fluctuations in mental status and for the following key words: agitation, confusion, disorientation, and hallucination.

Patients with a NEECHAM score $<25$ and/or positive results from a validated chart review were considered to have delirium. The onset and duration of delirium were also measured. All assessments of delirium were undertaken in a blinded manner without prior knowledge of perioperative beta-blocker or statin therapy.

Preoperative variables of interest

Preoperative variables incorporated in the database for analysis included: age, sex, diabetes mellitus, history of cerebrovascular accident (CVA) or transient ischemic attack (TIA), hypertension, coronary artery disease (CAD), preoperative creatinine, preoperative hemoglobin, history of depression, preoperative beta-blockers and statins. All variables were abstracted from patients' hospital charts. Preoperative beta-blocker therapy was defined as betablocker administration within one week prior to surgery.
Postoperative beta-blocker administration was retrieved from the electronic medication inpatient record. Diagnosis of preoperative depression was made on the basis of information provided by the referring physician and the patient's history.

Perioperative data collection

Data was obtained retrospectively from the hospital electronic data warehouse (EDW) database. Type of surgery, type of anesthesia (general, regional, combined general/ epidural, and local anesthesia with conscious sedation), and postoperative medications were obtained from the EDW.

Statistical analysis

\section{Univariate analysis}

Descriptive analysis was performed for the variables of interest. Associations between the outcome and the independent variables (demographic characteristic and clinical factors) were assessed with the Chi square and Fisher's exact tests for the categorical variables and the MannWhitney test for the continuous variables. The basis of the Mann-Whitney test, which was used to compare the onset times when patients developed delirium, was whether the beta-blockers were administered preoperatively or postoperatively.

\section{Multivariable analysis}

Multivariable analysis was performed with the use of ordinary logistic regression. In addition to perioperative betablocker and statins, a number of potential covariates were selected for the model. Evidence of direct association with the outcome has been previously suggested for each of those covariates. The total number of covariates was constrained so that, at most, it is equal to one-tenth of the number of patients with delirium. ${ }^{24} \mathrm{~A}$ simple backward model selection procedure was performed where non-significant covariates (Wald test, $P>0.3$ ) were removed from the model one by one. The overall performance and fitting of the model was evaluated at every step. Finally, when only significant covariates remained in the model, any variable not selected was returned to the model where its significance was re-evaluated and where it was potentially retained. This model selection procedure has been suggested previously for the identification of a parsimonious model. ${ }^{25}$

\section{Covariate effect}

The significance of the covariate effect was assessed by using the Wald test, with $P<0.05$ indicating a significant 
effect. The coefficient estimates, the odds ratios, and the $95 \%$ confidence intervals were calculated.

\section{Interaction effect}

The interaction effects of beta-blockers and other covariates were not investigated due to the large number of potential covariates and possible interactions. Such investigation would require a large number of additional tests of significance for those interaction terms, with doubtful inference. The lack of previous evidence of the effects of such interaction justified this decision.

\section{Goodness of fit}

The fit of the optimal model was assessed with various tests, including the Likelihood Ratio, Wald, and Score tests. These tests compared the selected model with the model without any covariate (intercept only). Low $P$-values indicated that the selected model fit with the data significantly better than the intercept-only model. An additional test for the fit of the model was completed using the Hosmer-Lemeshow test, where, given the selected model, actual event frequencies were compared with expected ones. Low $P$-values indicated a significant deviation and therefore a poor fit. Despite the purpose of our model being explanation rather than prediction, its discriminative power was assessed by using the Concordance Index for completeness purposes, which is equal to the area under the ROC curve. ${ }^{26}$ The linearity of the relationship between continuous predictors, such as age, and log odds of delirium was investigated visually using cubic splines. No obvious deviation from linearity was found. Finally, outlier and extreme influential observations were identified by visual inspection of residual plots and were further investigated.

\section{Model validation}

The model was validated internally using the Bootstrap resampling method. ${ }^{27}$ It is well known that the estimates of the performance of a model are biased when they are determined based on the data used for the construction of the model. Various methods have been proposed for dealing with this issue and for providing more accurate estimates of the model performance. Bootstrap, a very popular general tool for assessing statistical accuracy, is one of those methods. Random samples were drawn with replacement from the original data, each one of the same size as the original dataset. The model was fitted for each bootstrap sample and the coefficient estimates and standard errors for the variables of interest were output and stored. Subsequently, the Bootstrap confidence intervals of the odds ratio of beta-blockers and statins were calculated using the "Bootstrap- $t$ " method, ${ }^{28}$ and they were compared with the ones produced by the whole sample. Finally, the predictive strength of the selected model was validated by the area under the ROC curve using the non-parametric ".632" estimate. This estimate is equal to $0.368 * a p p a r-$ ent $+0.632 *$ average $($ test $)$, where apparent is the estimate using the whole dataset, and test is the estimate using a model trained in the bootstrap sample but applied to the subjects not selected in the sample. ${ }^{29}$ One thousand bootstrap samples were used for the validation.

The Bootstrap evaluation was applied only to the final selected model. Although we recognize that assessing the model selection procedure with Bootstrap would have strengthened our evidence for the fit of the selected model, we thought our backward selection procedure was performed with enough care where only variables with large $P$-values were excluded and then re-added and re-tested in subsequent models.

All statistical analyses were performed with $\mathrm{SAS}^{\circledR}$ version 9.1 (SAS Institute, Inc, Cary, NC, USA) and R version 2.5.0 (The R Foundation for Statistical Computing, Vienna, Austria) under a Windows ${ }^{\circledR}$ XP operating system.

\section{Results}

Of 828 patients who underwent vascular surgical procedures during the study period, $582(70 \%)$ satisfied the inclusion criteria. The NEECHAM assessment was performed in 531(91\%) patients. The median number of NEECHAM assessments performed was eight, with a range from 1 to 91, and the median length of hospital stay was 8 days, with a range of 2-231 days. The median NEECHAM score in patients with delirium was 21 (range from 15 to 24 ) compared with 28 (range from 27 to 30 ) in those without delirium. Demographic data and surgical characteristics are reflected in Tables 2 and 3.

Delirium was identified in 128 (22\%) patients during the hospital stay. Of these, 46 (36\%) patients were diagnosed with delirium on the first postoperative day (POD). A further 26 (20\%) patients developed delirium on the second POD. Thirty-nine $(30 \%)$ of the delirium cases developed from POD 3 to 5, and the remaining 17 (13\%) patients developed delirium from POD 6 to 18 .

The patients with delirium were older and suffered more often from preoperative CVA/TIA, CAD, and depression. Furthermore, they had lower hemoglobin levels and received preoperative beta-blocker therapy more often. Postoperative delirium developed more often after aortic reconstruction surgery and amputation. There was no difference with respect to the type of anesthesia between the two groups (Table 3 ). 
Table 2 Demographic data and incidence of postoperative delirium
$C A D$ coronary artery disease, $C V A$ cerebrovascular accident, EVAR endovascular aortic repair, TIA transient ischemic attack

Data is expressed as mean (SD), or number of patients (\%), or median [range]

Table 3 Types of anesthesia and surgical procedures and incidence of postoperative delirium
EVAR endovascular aortic repair

\begin{tabular}{lllc}
\hline & $\begin{array}{l}\text { Delirium/confusion } \\
\text { group }(n=128)\end{array}$ & $\begin{array}{l}\text { No delirium/confusion } \\
\text { group }(n=454)\end{array}$ & $P$ value \\
\hline Preoperative & & & \\
$\quad$ Age (years) & $71.4(10.7)$ & $66.9(13.0)$ & $<0.001$ \\
$\quad$ Sex (males) & $95(74 \%)$ & $319(70.2 \%)$ & 0.43 \\
$\quad$ Diabetes mellitus & $48(37.5 \%)$ & $144(32 \%)$ & 0.22 \\
Hypertension & $107(83.5 \%)$ & $372(82 \%)$ & 0.69 \\
History of CVA, TIA & $36(28.1 \%)$ & $66(14.6 \%)$ & $<0.001$ \\
$\quad$ History of CAD & $78(61.4 \%)$ & $222(49 \%)$ & 0.015 \\
$\quad$ Depression & $15(11.7 \%)$ & $15(3.3 \%)$ & $<0.001$ \\
Preoperative beta-blockers & $34(26.5 \%)$ & $81(17.4 \%)$ & 0.032 \\
Postoperative beta-blockers & $85(66.4 \%)$ & $280(61.7 \%)$ & 0.35 \\
Preoperative statins & $60(46.8 \%)$ & $251(55.4 \%)$ & 0.089 \\
Preoperative creatinine $\left(\mu \mathrm{mol} \cdot \mathrm{L}^{-1}\right)$ & $97[53-1113]$ & $90[35-936]$ & 0.07 \\
Preoperative Hb $\left(\mathrm{g} \cdot \mathrm{dL}{ }^{-1}\right)$ & $123(25.3)$ & $130(23.3)$ & $<0.001$ \\
\hline
\end{tabular}

\begin{tabular}{lccc}
\hline & $\begin{array}{l}\text { Delirium/confusion } \\
\text { group }(n=128)\end{array}$ & $\begin{array}{l}\text { No delirium/confusion } \\
\text { group }(n=454)\end{array}$ & $P$ value \\
\hline General anesthesia & $111(86.7 \%)$ & $396(87.2 \%)$ & 0.8 \\
Combined general and epidural anesthesia & $7(5.4 \%)$ & $24(5.2 \%)$ & 0.9 \\
Local anesthesia with conscious sedation & $7(5.4 \%)$ & $24(5.2 \%)$ & 0.9 \\
Regional anesthesia (epidural/spinal) & $3(2.3 \%)$ & $10(2.2 \%)$ & 1 \\
Amputation & $25(19.5 \%)$ & $39(8.5 \%)$ & $<0.001$ \\
Revascularization of lower extremities & $23(17.9 \%)$ & $123(27.1 \%)$ & 0.037 \\
Aortic reconstructive surgery & $38(29.7 \%)$ & $79(17.4 \%)$ & 0.003 \\
EVAR & $13(10.1 \%)$ & $93(20.5 .2 \%)$ & 0.004 \\
Thrombectomy/embolectomy & $19(14.8 \%)$ & $44(9.7 \%)$ & 0.11 \\
Other & $12(9.4 \%)$ & $76(16.7 \%)$ & 0.035 \\
\hline
\end{tabular}

The incidence of postoperative delirium was $29 \%$ in patients who received perioperative beta-blockers compared with $19 \%$ in patients who did not receive beta-blockers. There was no difference in the incidence of postoperative delirium between patients who started beta-blocker therapy postoperatively and those who were not treated with beta-blockers at any time perioperatively (20\% vs 19\%, respectively).

The median onset of delirium was POD 1 (range from 1 to 3 days) in patients who received beta-blockers

Table 4 Types and doses of beta-blockers administered preoperatively

\begin{tabular}{lcl}
\hline Beta-blocker & $\begin{array}{l}\text { Patients }(n) \\
(\text { Total } n=115)\end{array}$ & $\begin{array}{l}\text { Dose }(\mathrm{mg}) \\
(\text { median, range) }\end{array}$ \\
\hline Acebutalol & $2(1.7 \%)$ & N/A \\
Atenolol & $14(12.2 \%)$ & $25[25,100]$ \\
Bisoprolol & $13(11.3 \%)$ & $5[2.5,10]$ \\
Carvedilol & $2(1.7 \%)$ & N/A \\
Metoprolol & $84(73.0 \%)$ & $50[12.5,200]$ \\
\hline
\end{tabular}

preoperatively compared with POD 2 (range from 1 to 4 days) in patients who received beta-blockers in the early postoperative period $(P=0.038)$.

Preoperative beta-blockers were administered in 115 (19.8\%) patients (Table 4). All but two of these patients continued with beta-blockers postoperatively. A total of $252(43.2 \%)$ patients began beta-blocker therapy postoperatively, with oral metoprolol as the most frequently administered agent (Table 5). The beta-blocker therapy

Table 5 Types and doses of postoperative beta-blockers

\begin{tabular}{lcl}
\hline Beta-blocker & $\begin{array}{l}\text { Patients }(n) \\
(\text { Total } n=252)\end{array}$ & $\begin{array}{l}\text { Dose }(\mathrm{mg}) \\
\text { (median, range) }\end{array}$ \\
\hline Atenolol & $27(10.9 \%)$ & $50[25,100]$ \\
Bisoprolol & $38(15.3 \%)$ & $5[2.5,10]$ \\
Carvedilol & $4(1.4 \%)$ & $5[2.5,12]$ \\
Metoprolol & $177(70.3 \%)$ & $50[12.5,200]$ \\
Nadolol & $4(1.4 \%)$ & $20[20,40]$ \\
Propranolol & $2(0.7 \%)$ & 80 \\
\hline
\end{tabular}


Table 6 Independent predictors of postoperative delirium in patients undergoing vascular surgery
$C=0.746$, Hosmer and Lemeshow Goodness-of-Fit Test 0.72

CVA cerebrovascular accident, EVAR endovascular aortic repair, TIA transient ischemic attack

\begin{tabular}{llllr}
\hline Variable & $\begin{array}{l}\text { Coefficient } \\
\text { estimate }\end{array}$ & $\begin{array}{l}\text { Odds ratio } \\
\text { point } \\
\text { estimate }\end{array}$ & $\begin{array}{l}\text { 95\% Wald } \\
\text { confidence } \\
\text { interval }\end{array}$ & $P$ value \\
\hline History of CVA/TIA & 0.9728 & 2.64 & $1.57-4.45$ & $<0.001$ \\
Preoperative depression & 1.27 & 3.56 & $1.53-8.28$ & 0.003 \\
Age & 0.044 & 1.04 & $1.02-1.07$ & $<0.001$ \\
Preoperative beta-blockers administration & 0.7227 & 2.06 & $1.18-3.6$ & 0.011 \\
Preoperative statins administration & -0.2843 & 0.56 & $0.37-0.88$ & 0.011 \\
Type of procedure & & & & $<0.001$ \\
$\quad$ Amputation & 1.5396 & 4.66 & $1.96-11.09$ & $<0.001$ \\
$\quad$ Revascularization of lower extremities & 0.5462 & 1.73 & $0.77-3.85$ & 0.18 \\
$\quad$ Aortic reconstructive surgery & 1.6744 & 5.34 & $2.54-11.2$ & $<0.001$ \\
$\quad$ EVAR & 1 & 1 & - & - \\
$\quad$ Thrombectomy/embolectomy & 1.1844 & 3.27 & $1.41-7.6$ & 0.006 \\
$\quad$ Other & 0.2264 & 1.254 & $0.51-3.07$ & 0.6 \\
\hline
\end{tabular}

began anytime from the first to the tenth day after surgery, the median being POD 2.

After univariate analysis, the following predictors were selected for multivariate model selection (with the lowest $P$-values): pre- and postoperative beta-blocker administration, preoperative statins administration, age, preoperative depression, preoperative hemoglobin, preoperative blood glucose, preoperative creatinine, history of CVA and TIA, and the type of surgery. Endovascular aortic repair (EVAR) was chosen as the reference group due to its low rate of occurrence of delirium in comparison with other types of surgery.

After applying the model selection procedure, the following variables remained in the best fitted model: history of CVA/TIA, depression, aortic reconstruction surgery, amputation, preoperative beta-blockers administration, and preoperative statins therapy (Table 6). Adjusting for those variables, administration of statins had a significant protective effect (OR $0.56,95 \%$ (CI) $[0.370,0.88]$ ) Preoperative beta-blockers administration increased postoperative delirium (OR 2.06, 95\% CI [1.18, 3.6]) (Table 6). The model fitted well with the likelihood ratio test being significant $\left(\chi^{2}=84.8084\right.$ at $\left.10 \mathrm{df}, P<.0001\right)$. The Hosmer-Lemeshow test indicated good calibration $\left(\chi^{2}=\right.$ 5.3539 at $8 \mathrm{df}, P=0.72$ ). The c-index statistic, estimate of the area under the ROC curve, as calculated by PROC LOGISTIC in $\mathrm{SAS}^{\circledR}$, was equal to 0.746 . Validation using Bootstrap gave consistent results. The estimate of the area under the ROC curve was equal to 0.73 , while the "Bootstrapped" confidence intervals were very similar to those generated from the original dataset.

\section{Discussion}

The results of this study suggest that preoperative administration of beta-blockers is associated with higher delirium rates in patients undergoing vascular surgery. The rate of delirium was $29 \%$ in patients who received beta-blocker therapy throughout the perioperative period. Interestingly, if beta-blocker therapy did not begin until the postoperative period, the delirium rate was similar to that of the control group (20\% vs 19\%, respectively). Furthermore, the onset of delirium was significantly delayed in patients who received beta-blockers exclusively in the postoperative period. This finding is likely related to the fact that betablocker absorption is considerably reduced in the early postoperative period resulting in decreased bioavailability of orally administered preparations. ${ }^{30}$

It has been previously shown that perioperative administration of beta-blockers is associated with higher stroke rates in both surgical and non-surgical patient populations. ${ }^{18,31,32}$ Postoperative neurological complications can be related to both the cardiovascular and the central nervous system effects of beta-blockers. The common side effects of beta-blocker therapy include hypotension and bradycardia. ${ }^{17}$ These effects may result in reduced cerebral perfusion pressure and potentially diminished cerebral oxygen supply. Animal studies have shown that administration of beta-blockers prevents the compensatory increase in cerebral blood flow due to metabolic acidosis and sepsis. ${ }^{33,34}$ Furthermore, even in a non-stressful environment, aged hypertensive rats treated with propranolol showed decreased cerebral blood flow and worse cognitive function in comparison with animals treated with captopril. ${ }^{35}$ The presence of hallucinations, sleep disturbances, depression, ataxia, drowsiness, psychosis, and delirium are all recognized side effects of beta-blocker therapy. ${ }^{36-38}$ Furthermore, beta-blockers interact competitively not only with the beta adrenergic receptors but also with serotonin sensitive adenylate cyclase system, ${ }^{39}$ part of the important neurotransmitter network involved in pathogenesis of delirium. $^{40}$ Beta-blocker therapy also suppresses or 
abolishes the nocturnal secretion of melatonin, ${ }^{41,42}$ a neurohormone regulating sleep and circadian rhythms. Perioperative abnormal secretion of melatonin in the early postoperative period has been linked to postoperative delirium. ${ }^{43}$ Patients with existing cognitive dysfunction who were receiving beta-blockers experienced worse delayed memory retrieval and lower cognitive scores. ${ }^{44}$ In susceptible patients with a reduced number of hippocampal neurons (ischemia, Alzheimer's disease, etc.) the adrenergic receptor blockade might have caused further deterioration of memory decline and worsened already existing cognitive dysfunction. ${ }^{44}$

Our study re-confirms a number of previous reports that identify aortic reconstruction, preoperative depression, and cerebrovascular disease as risk factors for postoperative delirium. ${ }^{4,20,45,46}$ Complex vascular procedures and significant atherosclerosis reflected as severe peripheral or cerebrovascular disease may predispose patients to multiorgan dysfunction and delirium. Patients with vascular disease have lower reserve to cope with blood loss, hemodynamic instability, and inflammatory response associated with major vascular surgical procedures. Preoperative treatment with beta-blockers may exaggerate this lack of compensatory mechanism, decreasing the threshold for developing postoperative delirium. Although the previously reported incidences of delirium after vascular surgery are slightly higher, ${ }^{1,3,4}$ the current study included a broad spectrum of patients with a wide age range. In contrast to previous reports, we did not use age $>60$ as an inclusion criterion, and we did not limit the list of vascular procedures to open aortic reconstructive and peripheral bypass surgery. ${ }^{3-5,47}$ In order to reduce bias, we also excluded all patients undergoing carotid surgery from the analysis. Patients with uncomplicated carotid surgery usually had length of stay $<48 \mathrm{~h}$ and therefore did not meet our inclusion criteria. However, patients with symptomatic carotid artery disease and a complicated procedure may have experienced a higher incidence of perioperative cerebrovascular complications. The current report presents the largest cohort of vascular patients evaluated for postoperative delirium. Previous reports (with the largest sample size of 153 patients) ${ }^{47}$ might not adequately reflect the incidence of postoperative delirium in the full spectrum of patients who underwent vascular procedures.

Recently, we reported that preoperative administration of statins was associated with a lower risk of postoperative delirium in patients undergoing cardiac surgery. ${ }^{20}$ The current study confirms these findings, extending the beneficial role of statin therapy to the vascular surgical population. Conversely, a retrospective administrative cohort analysis in older patients undergoing elective surgery found statins to increase delirium. ${ }^{48}$ However, in that study identification of postoperative delirium was based solely on an administrative database which is likely not appropriate for detecting postoperative delirium. Previous research cautions us against using administrative data to measure postoperative complications. ${ }^{49}$ In contrast, our study prospectively applied validated screening tools for delirium.

This study has several limitations. The retrospective nature of the analysis may have underestimated the true incidence of postoperative delirium. However, we used validated tools for screening and diagnosis of postoperative delirium. Furthermore, our findings infer an association rather than a causal relationship between the preoperative beta-blocker therapy and delirium rates after vascular surgery. Consequently, future prospective trials would be required to validate these findings. A further limitation refers to the lack of postoperative variables as predictors of delirium. We deliberately focused only on pre- and intraoperative predictors and did not include any postoperative variables. Numerous postoperative events, such as hypotension, hypoxia, infection, sedatives, and narcotic analgesics, could all play a role in developing delirium after vascular surgery. However, a much larger sample size would be required to address these concerns. Since the intraoperative administration of beta-blockers is specifically under the auspices of the anesthesiologist, it would be important to evaluate its role in contributing to postoperative delirium. These limitations should be addressed in future trials investigating postoperative delirium and confusion in the surgical patient population.

Funding This work was supported by departmental funding.

Conflicts of interest None declared.

\section{References}

1. Balasundaram B, Holmes $J$. Delirium in vascular surgery. Eur J Vasc Endovasc Surg 2007; 34: 131-4.

2. Benoit AG, Campbell BI, Tanner JR, et al. Risk factors and prevalence of perioperative cognitive dysfunction in abdominal aneurysm patients. J Vasc Surg 2005; 42: 884-90.

3. Sasajima $Y$, Sasajima T, Uchida $H$, et al. Postoperative delirium in patients with chronic lower limb ischaemia: what are the specific markers? Eur J Vasc Endovasc Surg 2000; 20: 132-7.

4. Schneider F, Bohner H, Habel U, et al. Risk factors for postoperative delirium in vascular surgery. Gen Hosp Psychiatry 2002; 24: $28-34$.

5. Rosen SF, Clagett GP, Valentine RJ, Jackson MR, Modrall JG, McIntyre KE. Transient advanced mental impairment: an underappreciated morbidity after aortic surgery. J Vasc Surg 2002; 35: 376-81.

6. Franco K, Litaker D, Locala J, Bronson D. The cost of delirium in the surgical patient. Psychosomatics 2001; 42: 68-73.

7. Bohner H, Friedrichs $R$, Habel U, Muller EE, Sandmann W, Schneider F. Delirium increases morbidity and length of stay 
after vascular surgery operations. Results of a prospective study (German). Chirurg 2003; 74: 931-6.

8. Thomason JW, Shintani A, Peterson JF, Pun BT, Jackson JC, Ely $E W$. Intensive care unit delirium is an independent predictor of longer hospital stay: a prospective analysis of 261 non-ventilated patients. Crit Care 2005; 9: R375-81.

9. Francis J, Martin D, Kapoor WN. A prospective study of delirium in hospitalized elderly. JAMA 1990; 263: 1097-101.

10. Inouye SK. Delirium in older persons. N Engl J Med 2006; 354: 1157-65.

11. Lee TH, Marcantonio ER, Mangione CM, et al. Derivation and prospective validation of a simple index for prediction of cardiac risk of major noncardiac surgery. Circulation 1999; 100: 1043-9.

12. Fleisher LA, Beckman JA, Brown KA, et al. ACC/AHA 2007 guidelines on perioperative cardiovascular evaluation and care for noncardiac surgery: executive summary: a report of the American College of Cardiology/American Heart Association Task Force on Practice Guidelines (Writing Committee to revise the 2002 guidelines on perioperative cardiovascular evaluation for noncardiac surgery): developed in collaboration with the American Society of Echocardiography, American Society of Nuclear Cardiology, Heart Rhythm Society, Society of Cardiovascular Anesthesiologists, Society for Cardiovascular Angiography and Interventions, Society for Vascular Medicine and Biology, and Society for Vascular Surgery. Circulation 2007; 116: 1971-96.

13. Poldermans D, Boersma E, Bax JJ, et al. The effect of bisoprolol on perioperative mortality and myocardial infarction in high-risk patients undergoing vascular surgery. Dutch Echocardiographic Cardiac Risk Evaluation Applying Stress Echocardiography Study Group. N Engl J Med 1999; 341: 1789-94.

14. Brady AR, Gibbs JS, Greenhalgh RM, Powell JT, Sydes MR, POBBLE Trial Investigators. Perioperative beta-blockade (POBBLE) for patients undergoing infrarenal vascular surgery: results of a randomized double-blind controlled trial. J Vasc Surg 2005; 41: 602-9.

15. Yang H, Raymer K, Butler R, Parlow J, Roberts $R$. The effects of perioperative beta-blockade: results of the metoprolol after vascular surgery (MaVS) study, a randomized controlled trial. Am Heart J 2006; 152: 983-90.

16. Juul AB, Wetterslev J, Gluud C, et al. Effect of perioperative beta blockade in patients with diabetes undergoing major non-cardiac surgery: randomised placebo controlled, blinded multicentre trial. BMJ 2006; 332: 1482.

17. Bangalore S, Wetterslev J, Pranesh S, Sawhney S, Gluud C, Messerli FH. Perioperative beta blockers in patients having noncardiac surgery: a meta-analysis. Lancet 2008; 372: 1962-76.

18. POISE Study Group, Devereaux PJ, Yang H, et al. Effects of extended-release metoprolol succinate in patients undergoing non-cardiac surgery (POISE trial): a randomised controlled trial. Lancet 2008; 371: 1839-47.

19. Keller S, Frishman WH. Neuropsychiatric effects of cardiovascular drug therapy. Cardiol Rev 2003; 11: 73-93.

20. Katznelson R, Djaiani GN, Borger MA, et al. Preoperative use of statins is associated with reduced early delirium rates after cardiac surgery. Anesthesiology 2009; 110: 67-73.

21. Neelon VJ, Champagne MT, Carlson JR, Funk SG. The NEECHAM confusion scale: construction, validation, and clinical testing. Nurs Res 1996; 45: 324-30.

22. Inouye SK, Leo-Summers L, Zhang Y, Bogardus ST Jr, Leslie DL, Agostini JV. A chart-based method for identification of delirium: validation compared with interviewer ratings using the confusion assessment method. J Am Geriatr Soc 2005; 53: 312-8.

23. Djaiani G, Ali M, Borger MA, et al. Epiaortic scanning modifies planned intraoperative surgical management but not cerebral embolic load during coronary artery bypass surgery. Anesth Analg 2008; 106: 1611-8.

24. Peduzzi P, Concato J, Kemper E, Holford TR, Feinstein AR. A simulation study of the number of events per variable in logistic regression analysis. J Clin Epidemiol 1996; 49: 1373-9.

25. Hosmer DW, Lemeshow $S$. Applied logistic regression. 2nd ed. New York: John Wiley \& Sons, Inc.; 2000.

26. Agresti A. Categorical data analysis. New York: Wiley; 2002.

27. Efron B, Tibshirani RJ. An introduction to the bootstrap. New York: Chapman \& Hall; 1993.

28. Carpenter J, Bithell J. Bootstrap confidence intervals: when, which, what? A practical guide for medical statisticians. Stat Med 2000; 19: 1141-64.

29. Steyerberg EW, Harrell FE Jr, Borsboom GJ, Eijkemans MJ, Vergouwe $Y$, Habbema JD. Internal validation of predictive models: efficiency of some procedures for logistic regression analysis. J Clin Epidemiol 2001; 54: 774-81.

30. Halonen J, Hakala T, Auvinen T, et al. Intravenous administration of metoprolol is more effective than oral administration in the prevention of atrial fibrillation after cardiac surgery. Circulation 2006; 114(1 Suppl): I1-4.

31. Anonymous. MRC trial of treatment of mild hypertension: principal results. Medical Research Council Working Party. Br Med J (Clin Res Ed) 1985; 291: 97-104.

32. Anonymous. Medical Research Council trial of treatment of hypertension in older adults: principal results. MRC Working Party. BMJ 1992; 304: 405-12

33. Westerlind A, Larsson LE, Haggendal J, Ekstr om-Jodal B. Effects of arterial hypoxia, beta-adrenoceptor blockade on cerebral blood flow, oxygen uptake following $E$. coli endotoxin in dogs. Acta Anaesthesiol Scand 1995; 39: 472-8.

34. Westerlind A, Larsson LE, Haggendal J, Ekstrom-Jodal B. Effects of propranolol pretreatment on cerebral blood flow, oxygen uptake and catecholamines during metabolic acidosis following E. coli endotoxin in dogs. Acta Anaesthesiol Scand 1995; 39: 467-71.

35. Skinner MH, Tan DX, Grossmann M, Pyne MT, Mahurin RK. Effects of captopril and propranolol on cognitive function and cerebral blood flow in aged hypertensive rats. J Gerontol A Biol Sci Med Sci 1996; 51: B454-60.

36. Kogoj A. Suspected propranolol-induced delirium. Can J Psychiatry 2004; 49: 645.

37. Sirois FJ. Visual hallucinations and metoprolol. Psychosomatics 2006; 47: 537-8.

38. Conant J, Engler R, Janowsky D, Maisel A, Gilpin E, LeWinter $M$. Central nervous system side effects of beta-adrenergic blocking agents with high and low lipid solubility. J Cardiovasc Pharmacol 1989; 13: 656-61.

39. Costain DW, Green AR. Beta-adrenoceptor antagonists inhibit the behavioural responses of rats to increased brain 5-hydroxytryptamine. Br J Pharmacol 1978; 64: 193-200.

40. van der Mast RC, Fekkes D. Serotonin and amino acids: partners in delirium pathophysiology? Semin Clin Neuropsychiatry 2000; 5: $125-31$.

41. Brismar K, Hylander B, Eliasson K, Rossner S, Wetterberg L. Melatonin secretion related to side-effects of beta-blockers from the central nervous system. Acta Med Scand 1988; 223: 52530.

42. Stoschitzky K, Sakotnik A, Lercher P, et al. Influence of beta-blockers on melatonin release. Eur J Clin Pharmacol 1999; 55: 111-5.

43. Miyazaki T, Kuwano H, Kato H, et al. Correlation between serum melatonin circadian rhythm and intensive care unit psychosis after thoracic esophagectomy. Surgery 2003; 133 : $662-8$. 
44. Gliebus G, Lippa CF. The influence of beta-blockers on delayed memory function in people with cognitive impairment. Am J Alzheimers Dis Other Demen 2007; 22: 57-61.

45. Kazmierski J, Kowman M, Banach $M$, et al. Preoperative predictors of delirium after cardiac surgery: a preliminary study. Gen Hosp Psychiatry 2006; 28: 536-8.

46. Rolfson DB, McElhaney JE, Rockwood K, et al. Incidence and risk factors for delirium and other adverse outcomes in older adults after coronary artery bypass graft surgery. Can J Cardiol 1999; 15: 771-6.
47. Bohner H, Hummel TC, Habel U, et al. Predicting delirium after vascular surgery: a model based on pre- and intraoperative data. Ann Surg 2003; 238: 149-56.

48. Redelmeier DA, Thiruchelvam D, Daneman N. Delirium after elective surgery among elderly patients taking statins. CMAJ 2008; 179: 645-52.

49. Romano PS, Chan BK, Schembri ME, Rainwater JA. Can administrative data be used to compare postoperative complication rates across hospitals? Med Care 2002; 40: 856-67. 